\title{
Bringing Zull's Four Brain-derived Pillars of Learning into the English Classroom
}

\author{
Jorge Carlos Correa Rodriguez \\ Central China Normal University, Wuhan, China \\ jorgecorrear@yahoo.com
}

\begin{abstract}
Teaching modifies the brain of the learners. In that respect, providing teachers with information about ways in which the brain learns could allow them to enhance their practices. Similarly, language teachers should also embrace what experts and theories from Educational Neuroscience and Mind, Brain and Education Science (MBE) Science can offer to pedagogy. This paper explored Zull's biological learning model in order to provide a practical way to support language teaching. The model depicts 4 pillars derived from his understanding of the learning brain. Zull's model was developed by his observations of the organic structure of the brain. It originated from the functioning of specific areas located in the neocortex of the brain; the sensory area, the back-integrative area, the front-integrative area and the motor area. Zull (2002) posited that each area is in charge of general functions such as; gathering, reflecting, creating and testing respectively. This connection could benefit the teaching process by providing a path to follow at the moment of instruction. In that sense, this paper observed how his model could be connected with one language teaching methodology. Presentation, practice and production (PPP). It was also observed that the synergetic nature of the connections within the human brain allows the pillars to move throughout the stages of PPP. It means that despite each stage was bound to specific pillars, the rest of them could be also used in each particular stage of PPP if needed. Moreover, some suggestions for the general language classroom were also included. This paper, therefore, aimed to connect one theory derived from the understanding of the brain with pedagogy in order to enhance the way teaching and learning in language classrooms is conducted.
\end{abstract}

Keywords: biology of learning, the brain, zull's model, language teaching; PPP

How to Cite: Correa Rodriguez, J. C. (2020). Bringing Zull's four brain-derived pillars of learning into the English classroom. English Language Teaching Educational Journal, 3(1), 14-25

\section{INTRODUCTION}

Language learning, similar to any mental process, is strictly bounded to the inner and complex workings of the human brain (Friederici, 2017). Language is shaped due to the biological complexity of our brain, a process which has been also connected with aspects our evolution, such as the need for communication. It is not then surprising that language, as a mean of communication, is considered as a unique human characteristic, which is strictly bounded to the particular development of our species (Jackendoff, 2002). Thus, the intricate organic and cognitive processes which shape language, and learning itself, should not be an unknown subject for language teachers. According to Zull (2002), "(...) the more you understand the brain, the more artful you can be when you must teach" (p.vii). Consequently, language teachers' knowledge about how the brain learns may lead to improvements in the way languages are taught and therefore learned. For instance, language teachers may actually benefit from embracing what experts from Educational Neuroscience, and Mind, Brain and Education Science (MBE), which are two academic fields connecting brain science and education, have offered in respect to learning, teaching and several educational matters including 
language learning (Battro, Fischer, \& Léna, 2008; Caine, Caine, Klimek, \& McClintic, 2009; OECD, 2007; Sousa, 2011; Tokuhama-Espinosa, 2011; Tokuhama-Espinosa, 2014). All the investigations from those two areas can definitely have impacts on the quality of teaching and the way students actually learn. However, the success of that connection, to some extent, relies directly on educators' willingness to accept and include knowledge from those fields into their classrooms. For instance, in the words of Geake \& Cooper (2003), "(...) the education profession could benefit from embracing rather than ignoring cognitive neuroscience. Moreover, educationists should be actively contributing to the research agenda of future brain research" (p.7). Consequently, over the past years, numerous researchers have reflected on and promoted the critical connection between brain science and education to support teachers from all educational levels and academic subjects (Battro, Fischer, \& Léna, 2008; Blakemore \& Frith, 2005; Campbell \& Patten, 2011; Geake, 2009; Jensen, 2008; Sousa, 2011; Sousa, 2011; Willis, 2008), among others.

The rationale to developing this paper then originated by one main reason; the biological basis of language in the brain. It means that if language is originated in the brain, then a higher understanding of the way the brain learns may lead to enhancements in the way language is taught. Moreover, since Zull's model depicts an organic way of learning, then the possible connections between language teaching and his learning model were believed to be appropriate. Finally, since his model describes learning as a universal process happening in the brain, then language learning would be included, and it could be taught by following the ideas within his model. Thus, this paper will particularly examine in which ways Zull's four learning pillars could be connected to one well known language teaching methodology presentation, practice and production (PPP). The four pillars being connected with language teaching will be; gathering, reflection, creating and testing as presented in his model (Zull J. E., 2002; Zull J. E., 2006; Zull J. E., 2011).

The first section of this paper will explore the main theory behind Zull's four pillars in order to describe its theoretical foundations. The second section will firstly include a reflection on how the 4 pillars can be connected with one PPP. Finally, some practical and general ideas to connect the pillars with the English language classroom will be presented.

\section{Zull's biology of learning}

The main theory supporting this paper was developed by Zull (2002) when connecting Kolb's experiential learning cycle (Kolb, 1984, 2015) with his knowledge of the human brain and the biology of learning. Zull proposed the construct of learning as a 4 stage physio-biological process involving, broadly speaking; the sensory, integrative and motor areas in the brain. Moreover, Zull observed learning as a process which produces physical changes in the structure of the brain. In his own words (2002), "Learning is about biology" (p.xiii). However, even though he acknowledged learning as a far more complex process including a variety of parallel and overlapping interconnections, he insisted that in end, the 4 pillars could be considered as the main framework where all the interconnections of the biological learning processes are encased and happen in an orchestral but no rigid fashion. To sum up, and based on Zull's ideas, we could define learning as a physical and cognitive experience encasing the integration, processing and assimilation of sensory stimuli from the environment and the body resulting in concrete and dynamic motor responses. This definition could 
also apply to language learning because it includes some actions similarly performed by language teachers.

\section{Zull's four fundamental pillars of learning}

Zull's four pillars of learning have some organic foundations which depict four major areas of the neocortex as observed below. Thus, an overview of these structures of the brain will be firstly included.

\section{The 4 major areas of the neocortex supporting the pillars}

These areas are, in general terms, in charge of gathering, reflecting, creating, and testing all data around and within us. The way in which these areas of the human brain interact in complex manners are believed to set the basis for our capacity to learn. In consequence, and before going into the four pillars, it is necessary to identify and describe the 4 major areas of the neocortex carrying out most learning processes. As described in Zull's model (2002), they are the following; the sensory area (gathering), the back-integrative area (reflecting), the front-integrative area, (creating) and the motor area (testing) as clearly observed in figure 1.

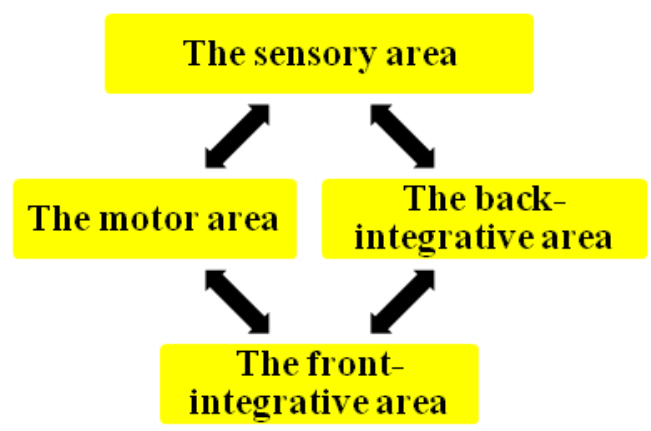

Figure 1. The 4 Major Areas of the Neocortex in the Human Brain (Zull J. E., 2002)

From the previous diagram, it can be observed that the relationship between those four areas is not linear; it is actually a cycle which can include several processes and sub-processes within each area, all of them happening and overlapping simultaneously.

The sensory area: The sensory area of the neocortex is in charge of receiving and gathering all the stimuli coming from the environment around us, as well as from our own bodies. This process is facilitated by all the senses human beings have. For example, the senses of sight and hearing allow us to see the light, images and hear sounds in the outside world. Therefore, all the senses in the body play a fundamental role as receptors of information encased in the stimuli which will be processed later on in other areas of the neocortex connected to each specific sense. This particular collection of data is fundamental for all of us because it helps us to observe, understand and interact, as well as to learn from the environment we live on. In sum, all we can sense, feel, see, hear, taste, touch etc, is firstly received in the sensory area of the neocortex in the human brain. Later on, this data will be internalized. 
The back-integrative area: Once the information from the stimuli has entered the sensory cortex and its particular nature has been identified, it may be immediately directed to the back integrative area of the neocortex for deeper association. The processes in this area can also be parallel and even overlap each other depending of the experience. Moreover, in this area of the neocortex, the data is also processed and combined with existing data; it means it is connected with existing information in the memories of the person. This is a fundamental aspect of the learning process, the association between the new and the previous knowledge. In sum, in the backintegrative area the sensory information is integrated in order to obtain meaning out of the data received previously through the senses by connecting it with previous knowledge.

The front-integrative area: In the next area of the neocortex, the data is consciously internalized due to our cognitive skills. It is in this stage where we can identify the data, as a construct itself which we can cognitively understand resulting in judgments and decisions. Similarly, when the information reaches this area, we can comprehend its meaning and apply and attach our own thinking to it. One extra process happening here is the identification of its relevance and usefulness for the learning experience itself. In sum, the front integrative are of the neocortex is in charge of the consciously processing of the information, it also allows us to plan actions and make decisions on the possible ways we can actually try out hypothesis derived from the information within the learning experience in which we are at.

The motor area: The motor area of the neocortex is what allows us to, after all the integrative and associative processes, to react to the stimuli we have initially received. This active and motor reaction is bounded to the meaningful understanding, and hopefully successful processing, of the data within the stimuli. It is then due to this specific area by which our actions can illustrate a real connection between the stimuli and our particular thinking derived from the assimilation process the information, which was contained in it. For instance, a clear illustration would be the ability to orally reply to a question in our own, or for the sake of this paper, in a foreign language. In sum, the motor are of the neocortex facilitates our "reaction" to the stimuli we have received. It means that after all the reflective and integrative processes originated from the assimilation of the sensory data of the stimuli, we can finally show a cognitive and bodily understanding of that sensory experience through actions. Figure 2 shows the location of the areas of the neocortex in the human brain, the picture below was obtained from (Zull J. E., 2002) (p.15).

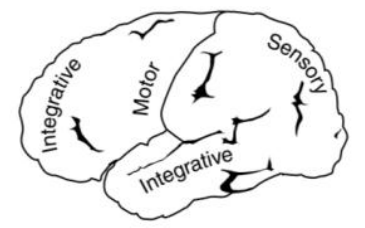

Figure 2. The Four Areas of the Neocortex

\section{The four pillars or learning}

The four pillars in Zull's model of learning are; gathering, reflecting, creating, and testing. In this section, each pillar will be described, in general terms, aiming to set the basis for the upcoming connections with the English language classroom. A visual representation of the four pillars is presented in figure 3 . 


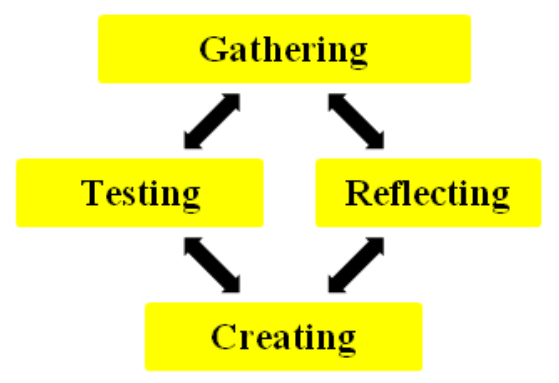

Figure 3. Zull'S Four Pillars of Learning (Zull J. E., 2002)

\section{Pillar One: Gathering data}

The first pillar, similarly to its corresponding section of the neocortex, is related to information or data gathering. In order to learn, people need to actively interact with the world around them. We need to have access to concrete experiences and meaningful interactions. It is in this way how we are able to "absorb" and assimilate the information we will use in situations like surviving, socializing, and of course learning a language. The gathering of data, within any learning experience, is a critical step which should include the activation of all senses and it should hopefully origin from concrete experiences (Zull J. E., 2002). The more senses involved in any learning situation, the more regions of the brain are activated. Thus, if more senses are involved in the gathering of data, these processes then may ignite the activation of more neurons and therefore the activation of more neural connections leading to the creation of complex networks within the brain. In sum, the brain relies on its biological mechanisms to gather data through, hopefully from a complete sensory-based experience.

\section{Pillar two: Reflecting}

Once the brain has received and gathered information from the environment, this data needs to be connected in order to make meaning. Thus, in this stage, the assimilation of all the pieces of information occurs by creating associations for instance with the existing information. It means that the data which entered the brain is somehow "grouped" with other pieces of data in order to get some meaning out of it. This process may be considered as one of the fundamental aspects in the learning of a language due to its connective nature. It is in this stage where the learner actually creates connections between the new data with existing knowledge in the brain. Moreover, this new knowledge is also classified based on its relevance for that specific experience, as well as related to the recall of previous knowledge coming from the memories of the individual (Sousa, 2011). Similarly, the reflecting stage of the learning process is the one which facilitates, activates and produces memory formation due to the connectivity nature of its functioning. In simple words, the brain connects the incoming information with the already processed information by means of reflection. So teachers need to guide students to create connections. 


\section{Pillar three: Creating}

At this stage, the brain performs processes related to conscious reflection and planning. Moreover, it creates intentional and purposeful associations. It is in this stage where we test hypothesis and develop action plans to be performed with the information encased in the learning experience. It is in fact what we will actually do with the data we have received. Most of these action plans will be tested out in the next stage; however, some of them may not be used and could be replaced with ideas which may be considered to be more appropriate and useful for the experience. A selective process aiming to state relevance and meaningfulness may also appear at this stage. The level of metacognitive skills a person may have can similarly enhance or hinder the process. It means that the capacities a person may have to create meaning from what they learn may be observed in this stage. Students at this point think and consciously observe the usefulness and possible ways in which learning a specific topic may benefit them as well as what they can do with that information.

\section{Pillar four: Active testing}

This pillar encases the active testing of the action plans originated in the previous stage. It is in this stage where learners can observe if their predictions or hypothesis from the previous stage were effective. It means that the brain of the students after receiving, associating and planning what to do with the stimuli they received can finally try their ideas out in the real world. If the actions plans for some reason fail, they can start the process again and retest their ideas. This pillar, similarly to the first one has the experience-based foundations of Zull's model of learning. Its relevance originates from the concrete usage of the information after all the internal systems dealt with the stimuli entering the body. In sum, students need to be given time to try out their ideas in concrete and active manners.

The four pillars described in this section provided a general view of data processing in the brain, which according to Zull, should be seen as the foundation of all learning. His model represents a general way of information processing which teachers could use to enhance their practices.

\section{RESEARCH METHOD}

This paper followed a library research method. It means that the corresponding information and theories depicting the main ideas supporting the study were drawn after revising and understanding the selected theorists' books. Hence, a description of the major foundations was initially observed, and then the possible applications of the theory were connected with English teaching.

\section{FINDINGS AND DISCUSSION}

This section will aim to connect Zull's model with one language teaching methodology; (PPP) presentation, practice production (Harmer, 2007a; Harmer, 2007b). This methodology was selected because it was believed that most English language teachers should be familiar with the theory behind it. In future research, other methodologies could be observed.

\section{Presentation, practice, production (PPP) and the four overlapping pillars}

If we think about language teaching we can recall the idea of presentation, practice and production. PPP depicts a specific way in which language or particular features of a language can be taught. For a more detailed description of PPP, please 
refer to (Harmer, 2007a: Harmer, 2007b). In general terms, when teachers use PPP, learners are firstly presented with a language feature. At this point, the sensory cortex allows the brain to gather the incoming information. Then, learners need to internalize it by means of practice and reflection. In other words, they need to reflect and use the information; some testing could also be needed at this stage if needed. Finally, learners should produce the same or new language derived from what was presented. Therefore, they have to try or test if the way in which they processed the information was correct based on the requirements of that particular learning situation. The overlapping nature of the model allows each area and each pillar to move from one stage to the other. It means that despite, to some extent, the fixed structure of PPP, the pillars can overlap as needed. Zull's idea of the model relied on the synergetic nature of the human brain, even though it follows certain patterns, its uniqueness relies on its capacity to create infinite connections to enhance its functioning. For example, practice can include two or more areas of the neocortex at the same time as observed in figure 4 . In other words, learners may rely on different parts of the brain to integrate information in order to practice and produce the target language. For instance, even though at the presentation stage learners mainly receive and gather information, they may also reflect and test some ideas related to the topic they are learning in that specific initial stage. For those reasons, despite the 4 pillars were included in each stage in the figure below, the most relevant(s) for that specific stage will be presented in italics. To sum up, figure 4 was mainly included to clarify Zull's theory rather than to rigidly provide a pattern to follow. The main idea was to try to observe how PPP could mirror the pillars and how they could be placed along all the stages. It is relevant to mention again that due to the synergetic and intricate nature of the biological processes within the human brain, the 4 pillars of learning can overlap and therefore be activated through the 3 stages of PPP.

\begin{tabular}{|c|c|c|}
\hline Presentation & $\begin{array}{l}\text { Sensory area of the } \\
\text { neocortex }\end{array}$ & $\begin{array}{c}\text { Gathering/Reflecting/Creating/ } \\
\text { Testing }\end{array}$ \\
\hline Practice & $\begin{array}{l}\text { Back, frontal } \\
\text { integrative and motor } \\
\text { areas of the neocortex }\end{array}$ & $\begin{array}{c}\text { Gathering/Reflecting/Creating/ } \\
\text { Testing }\end{array}$ \\
\hline Production & $\begin{array}{l}\text { Motor area of the } \\
\text { neocortex }\end{array}$ & $\begin{array}{c}\text { Gathering/Reflecting/Creating/ } \\
\text { Testing }\end{array}$ \\
\hline
\end{tabular}

Figure 4. The Connection between PPP and the 4 Pillars of Learning

\section{The 4 pillars in the general English classroom}

Pillar 1. Data gathering: Include learning experiences which promote the highly inclusion and activation of all the senses. Make learning experiential!

In order to apply Zull's model, educators should start by designing learning experiences which include the ideas behind the first pillar. The first pillar deals with the 
sensory gathering of the information because we receive most of the input from the environment. Thus, language teachers should do their best to turn their classes into highly sensorial learning experiences. It is relevant to mention that these will be general ideas, it is then the task of the teachers to use their creativity and adaptation skills to apply the first pillar into their particular contexts and needs. Following, a set of specific ideas to include the first pillar into language classes

a) When dealing with vocabulary, teachers should use pictures, videos, realia and include concrete experiences to introduce it. According to Zull's first pillar, this may facilitate the creation of more complex and integrated networks in the brain because once the input enters the brain more senses will be involved. It means that if students see, hear, touch, and taste an object related to one specific word for example, this construct will be connected to "four neuronal networks". Of course that there may be more networks involved, but here we oversimplify the idea to make things clear. Following the example, the resulting activated networks would be the visual, auditory, tactile and gustatory. On the contrary, if students just look at a word on a flashcard or written on the board, they may lack the opportunity to create more networks for that specific word which may probably later on hinder memory formation.

b) If possible, take students out to field trips so they can learn and use language on the spot. For instance, a zoo, a museum, a park. This will allow them to interact with the stimuli in the environment while using the target language. Concrete experiences activate and involve more neuronal networks.

c) Bring the outside world into your classroom. Turn your classroom into a post office, a hospital, a restaurant, an amusement park etc. Be creative!

d) Ask students to bring from home realia related to the topics they are learning. This could also add the affective connection with the learning experience.

e) Use songs, drawing books, scale models, plasticine. etc. Make learning active and more organic, so not only visual and auditory sections of the brain will be activated.

Pillar 2. Reflection: Guide students to connect and associate the new information with previous experiences. Neurons that fire together, wire together (Hebb, 1949).

Once the data has been received, something must be done with it. So now it is reflection time! Provide enough time for students to reflect on what they are learning with what they already know. However, learning is more than receiving data from the environment through the senses and to think about it is not enough; something very important needs to be done with that data. What it is needed at this point is the creation of connections. Moreover, they have to be highly effective connections which should be achieved thanks to the reflection processes. It means that learners should be guide to effectively associate the new input or data with existing ideas in their memory systems. Thus, they need to attach new knowledge entering through the senses with previous related knowledge stored in their brains. The following are some ways in which this can be possibly achieved.

a) Use the art of questioning, it means that you can use specific questions to make students think, connect and associate the new information with previous experiences. Recalling! 
b) Provide "thinking time". Let students go into their memories to create those connections.

c) Encourage students to use mind maps to connect ideas.

d) Allow students to interact and share ideas with peers

e) Provide clues and guide them to make effective connections.

f) Allow students to interact in groups

Pillar 3. Creating: Guide students to generate and develop ideas based on the connections they have formed.

This specific pillar may allow students to develop a sense of deep understanding of the data they have received and processed in the previous stages, and actually plan and try out what to do with it. This is actually the stage in which students use their cognitive capacities to consciously think and give meaning to knowledge, as well as to generate some potential final outputs. This capacity to think about what is being learned leads to the planning of the actions to be performed in the next stage. Students can therefore mentally prepare themselves to try out a hypothesis or ideas connected to the element or topic they are dealing with. This stage provides them with the opportunity to personalize and connect their own thinking with the learning experience by becoming cognitively active manipulators of the knowledge. This could be considered as a cognitive trial an error process. Here students plan and test their ideas because it is a fully metacognitive stage. Below, some ideas to get the best out of this pillar.

a) Provide appropriate time for students to reflect and try out their mental ideas.

b) Celebrate mistakes as part of the learning process!

c) Encourage students to think about learning. Promote critical thinking.

d) Show them ways to enhance their metacognitive skills.

e) Guide the reflection by being a supporter rather than a corrector.

f) Promote creativity among your students.

Pillar 4. Testing: See learning as an experiential process where students can test their ideas.

After the data, content or knowledge passed the previous pillars, students need to test the ideas specifically developed in the reflection and creating pillars. It means that they need to have the opportunity to observe how their assumptions on the new knowledge, which was already processed, can be applied or tried out. This stage may provide a concrete way to meaningfully use the data which was received, associated and integrated in the first stages. Similarly to the previous stage, in the last pillar, students will also experience mistakes at the moment of trying out their ideas. It is then the task of the teacher to guide and make them aware of the importance of mistakes as fundamental part of learning. In the case errors are done, they should be encouraged to rethink and reconsidered their hypothesis or ideas in order to retry them until they get it right. This, in the end, should produce a new sensory and concrete experience and the cycle may start all over again.

a) The inclusion of acting and role plays in the language classrooms are specific ideas related to the last pillar. These two, and other similar activities, may allow 
students to fully and bodily immerse themselves in the use of language. In a class performance, the students will use all their bodies and senses to communicate when acting out. In other words, they would be actively testing and integrating knowledge within an experiential process.

b) At this point it should be mentioned that the performance of dialogues in front of the class may a little distant from the pillars because, in general, students mainly read aloud from their notes or a given handout. The idea is to make learning a highly sensorial experience in which they were active participants. So, encourage students to be creative by developing their own dialogues using the target language.

c) Encourage students' active participation!

d) Similar to the previous pillar, celebrate mistakes as part of the learning process.

e) Design your classes so all students can use the target language in experiential and active fashions.

The previous examples included some general ideas to include the four pillars in the English classroom. However, considering the vast amount of specific topics, levels and contexts related to language learning, it was decided to include mainly some broad ideas for the teacher. It is then recommended that teachers should use their creativity to include the pillars when designing their classes because as observed in Zull's model, that is how the brain actually learns.

\section{CONCLUSION}

In general words, this paper reflected on the connection between Zull's biological model of learning and one language teaching methodology; presentation, practice and production. It overviewed Zull's model main foundations rooted in some of the major areas of the brain; the sensory, integrative and motor areas of the neocortex. Similarly, it observed how Zull connected those areas of the brain with learning itself by proposing 4 pillars depicting a natural, but not fixed, cycle of learning. It also included a reflection on how one language teaching methodology (PPP) may connect to the pillars. It was also observed that the synergetic nature of the connections within the human brain allows the pillars to move throughout the stages of PPP, it means that despite each stage was bound to specific pillars; the rest of them could be also used in each particular stage of PPP if needed. Moreover, it included some general ideas to incorporate each pillar into the language classroom. It is relevant to mention that this paper mirrored a similar review which observed the ways in which other learning principles found within (MBE) Science could be similarly included into the English classroom (Correa Rodriguez, 2018).

To sum up, learning involves mental and physio-biological process. Educators then should take into account both aspects of learning when designing and conducting their classes. They should not focus only on the cognitive aspects of learning; they should also pay attention to how the brain organically processes that knowledge and bring that information into their classrooms when possible. As Zull, (2002) stated, “(...) learning is change. It is change in ourselves, because it is change in the brain. Thus, the art of teaching must be the art of changing the brain" (p.xiv). Hopefully, Zull's model of learning can provide a different perspective for teachers to use so they can enhance their practices and make learning a more organic-based experience. 


\section{REFERENCES}

Battro, A. M., Fischer, K. W., \& Léna, P. J. (2008). The educated brain. Essays in neuroeducation. New York: Cambridge University Press.

Blakemore, S.-J., \& Frith, U. (2005). The learning brain. Lessons for education. Oxford: Blackwell.

Caine, R. N., Caine, G., Klimek, K. J., \& McClintic, C. (2009). 12 Brain/mind learning principles in action. Thousand Oaks, CA: Corwin Press.

Campbell, S. R., \& Patten, K. E. (2011). Educational neuroscience: Initiatives and emerging issues. West Sussex: Wiley-Blackwell.

Correa Rodriguez, J. C. (2018). Connecting English language teaching with 12 brain/mind learning principles. International Journal of Indonesian Education and Teaching, 2(2), 161-169. https://doi.org/10.24071/ijiet.2018.020208

Friederici, A. D. (2017). Language in our brain: The origins of a uniquely human capacity. Cambridge, Massachusetts: The MIT Press.

Geake, G. J. (2009). The brain at school. New York: McGraw-Hill Companies.

Geake, J., \& Cooper, P. (2003). Cognitive neuroscience: Implications for education? Westminster Studies in Education, 26(1), 7-20. https://doi.org/10.1080/0140672030260102

Harmer, J. (2007a). How to teach English: An introduction to the practice of English language teaching (2nd ed.). Essex: Pearson Education Limited.

Harmer, J. (2007b). The practice of English language teaching (4th ed.). Essex: Pearson Education Limited.

Hebb, D. O. (1949). The organisation of behavior. New York: Wiley.

Jackendoff, R. (2002). Foundations of language: Brain, meaning, grammar, evolution. New York, U.S.A: Oxford University Press Inc.

Jensen, E. (2008). Brain-based learning. Thousand Oaks: Corwin Press.

Kolb, D. A. (1984). Experiential learning: Experience as the source of learning and development. New Jersey: Prentice-Hall.

Kolb, D. A. (2015). Experiential learning: Experience as the source of learning and development (2nd ed.). New Jersey, U.S.A: Pearson Education, Inc.

OECD. (2007). Understanding the brain: The birth of a learning science. Centre for Educational Research and Innovation. OECD.

Sousa, D. A. (2011). How the brain learns. Thousand Oaks: Corwin.

Sousa, D. A. (2011). How the ELL brain learns. Thousand Oaks : Corwin.

The Royal Society. (2011). Brain waves module 2. Neuroscience: Implications for education and lifelong learning. London. The Royal Society.

Tokuhama-Espinosa, T. (2011). Mind, brain and education science. New York: W.W. Norton \& Company, Inc.

Tokuhama-Espinosa, T. (2014). Making classrooms better: 50 practical applications of mind, brain and education science. New York: Norton.

Willis, J. (2008). How your child learns best. Naperville: Sourcebooks Inc.

Zull, J. E. (2002). The art of changing the brain. Enriching the practice of teaching by exploring the biology of learning. Virginia: Stylus Publishing, LLC.

Zull, J. E. (2006). Key aspects of how the brain learns. In S. Johnson, \& K. Taylor (Edits.), The neuroscience of adult learning: New directions for adult and 
continuing education, (pp. 110, 3-9). U.S.A. Jossey-Bass. https://doi.org/10.1002/ace.213

Zull, J. E. (2011). From brain to bind: Using neuroscience to guide change in education. Sterling: Stylus Publishing. 